\title{
Theoretical investigation of the effect of the taper angle of the deforming roller on the limiting degrees of deformation in the process of flow forming
}

\author{
Andrey A. Udalov ${ }^{1,}{ }^{*}$, Sergey $V$. Parshin ${ }^{1}$, and Aleksandr $V$. Udalov ${ }^{2}$ \\ ${ }^{1}$ Ural Federal University named after the first President of Russia B.N. Yeltsin, 19, Mira Street, \\ Ekaterinburg 620002, Russia \\ ${ }^{2}$ Vyatka State University, 36, Moskovskaya Street, Kirov 610000, Russia
}

\begin{abstract}
The conditions for the application of taper angles of deforming rollers are considered in the article, which ensure a steady flow of the flow forming. With the help of the developed engineering technique, analytical and graphical dependences of the boundary values of the deformation degrees on the cone angle of the deforming roller are obtained. The results of the theoretical study are in good agreement with the known experimental data. The developed engineering technique can be used in designing the flow forming on the direct and reverse method, as well as for any process of pressure treatment with a local focus of deformation.
\end{abstract}

\section{Introduction}

In recent years, in the machine-building industry, the most dynamically developing technologies are the processing of metals by pressure with the creation of a local zone of deformation [1-8]. One such process is the flow forming of cylindrical parts [9-13], which is usually performed by a conical roller in a forward or reverse manner (Fig. 1). The qualitative performance of this operation depends on the correct choice of technological regimes and the corresponding geometric parameters of the deforming roller. The steady flow of the process of the flow forming depends mainly on the angle of the cone of the roller $\alpha$. In existing literary sources it was noted that the optimum values of the angle of conicity $\alpha$ are in the range from $15^{\circ}$ to $30^{\circ}[2,9-11,13-17]$.

In general, the results of studies on the choice of angle coincide $\alpha$ with the experimental data, but there are no simple engineering techniques that allow assigning geometric parameters of the deforming roller, depending on the required deformation conditions. The existing methods of theoretical investigation are rather complicated $[10,11$, $18,19]$, which to a considerable extent makes their application difficult at the design stage of the flow forming process.

* Corresponding author: h1008he4003@gmail.com 
The aim of the article is to develop an engineering technique that allows assigning a cone angle of a deforming roller, depending on the required degree of deformation of the wall of the tubular blank in the process of flow forming.

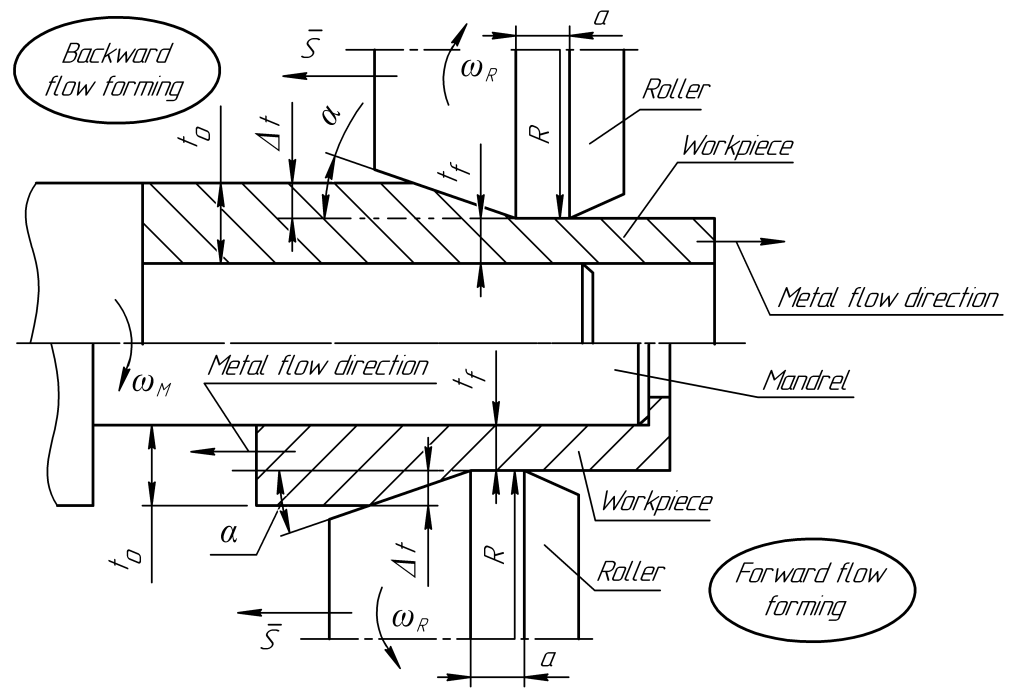

Fig. 1. Schematic diagrams of flow forming: $\omega_{M}$ - the angular velocity of the mandrel; $\omega_{R}-$ the angular velocity of the roller; $\bar{S}$ - axial feed of roller; $\alpha$ - the cone angle of the roller; $t_{o}$ and $t_{f}-$ the initial and final wall thickness of the tubular blank; $\Delta t$ - absolute deformation of the workpiece wall; $R$ - roller radius; $a$ - the width of the calibrated roller belt

\section{Development of engineering method}

The proposed engineering methodology is based on the main provisions on the local nature of the deformation zone and the approximate model of propagation of plastic deformation $[20,21]$. In accordance with this model, slip cones formed on the contact surfaces of the workpiece with deforming elements are constructed, which in this case are a roller and a mandrel (Fig. 2 and Fig. 3). To obtain a relationship between the degree of deformation and the cone angle $\alpha$, the axial sections of the cones of slip located in the plane passing through the axis of rotation of the roller and the workpiece are constructed.

The figure $\mathrm{ABC}$ is the axial section of the slide cone formed by the roller and the outer surface of the workpiece. The figure EFG is the axial section of the slide cone formed by the mandrel and the inner surface of the workpiece. In order to obtain the required dependence of the degree of deformation on the taper angle of the roller, two variants of the mutual arrangement of the slip cones are considered (ABC and EFG).

\subsection{The first variant of the mutual arrangement of the cones of sliding (Fig. 2)}

The vertexes of cones $\mathrm{C}$ and $\mathrm{E}$ are on the line DE parallel to the axis of the workpiece, and the distance between them in the radial direction is zero. This arrangement of slip cones ensures uniform distribution of deformations along the thickness of the workpiece wall, as well as the absence of metal buildup in front of the roller during the processing. 


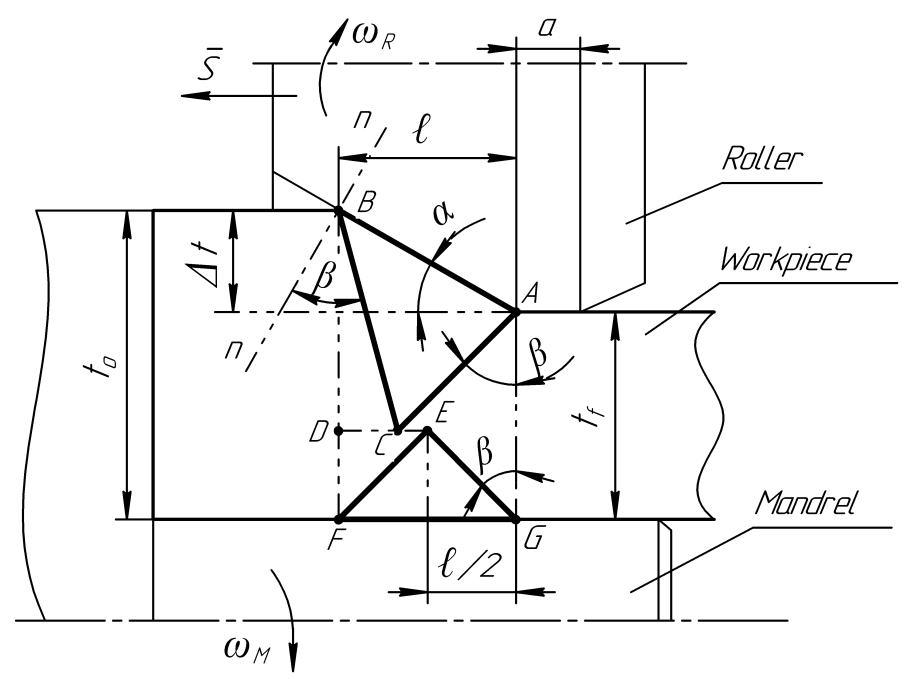

Fig. 2. Drawing of cones of sliding (the first variant): $\ell$ - length of the geometric zone of deformation; ABC - section of a cone of sliding formed by a roller and a workpiece; $E F G$ - section of the slip cone formed by a mandrel and a workpiece; $\beta=45^{\circ}$ - the angle of inclination of main shearing stress lines; $n-n$-perpendicular to the generatrix of roller $\mathrm{AB}$

The relationship between the required degree of deformation and the taper angle of the roller $\varepsilon=\varepsilon(\alpha)$ was obtained using the standard formula for the degree of deformation of the pipe wall in processes of flow forming $[9-11,18]$ :

$$
\varepsilon=\frac{t_{o}-t_{f}}{t_{o}}=\frac{\Delta t}{t_{o}} .
$$

In accordance with Fig. 2, the following substitutions are performed in the Eq. 1 (on condition $\beta=45^{\circ}$ ):

$$
\begin{gathered}
\Delta t=\ell \cdot \operatorname{tg} \alpha \\
t_{o}=B D+D F=\ell \cdot\left(\frac{\cos ^{2}\left(45^{\circ}-\alpha\right)}{\cos ^{2} \alpha}+\frac{1}{2}\right) .
\end{gathered}
$$

After substituting Eq. 2 and Eq. 3 into Eq. 1, we obtain the required dependence $\varepsilon=\varepsilon(\alpha)$ for the first variant of the mutual arrangement of the cones (Fig. 2):

$$
\varepsilon=\frac{2 \operatorname{tg} \alpha}{\operatorname{tg}^{2} \alpha+2 \operatorname{tg} \alpha+2} .
$$

According to the Eq. 4, plot 1 is plotted, which is shown in Fig. 4. Graph 1 actually determines the boundary value of the angle $\alpha$ for a given value of the degree of deformation $\varepsilon$. Exceeding the taper angle of the roller of the boundary value causes 
unevenness in the distribution of plastic deformation along the wall thickness and, as a consequence, the formation of a flowed metal.

\subsection{The second variant of the relative arrangement of the cones of sliding (Fig.3)}

The axial sections of the slip cones $\mathrm{ABC}$ and $\mathrm{EFG}$ overlap by a distance equal to the height of the cone EFG and form the intersection region of the EKCM. This arrangement of cones is the limiting value of the deforming forces.

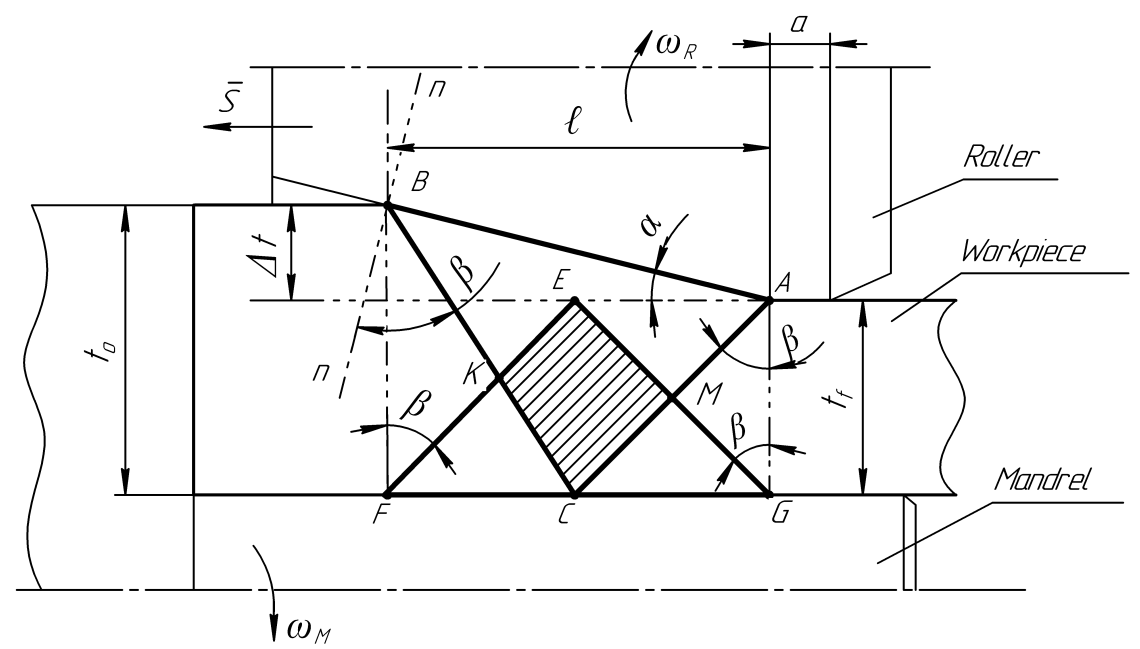

Fig. 3. Construction of cones of sliding (second option)

The dependence $\varepsilon=\varepsilon(\alpha)$ corresponding to the second variant of the arrangement of the slip cones was obtained using Eq. 1 . The value $\Delta t$ is determined by the Eq. 2 , and the initial thickness of the blank wall is represented in the form (on condition $\beta=45^{\circ}$ )

$$
t_{o}=B C \cdot \cos (\beta-\alpha)=\ell \cdot \frac{\cos ^{2}\left(45^{\circ}-\alpha\right)}{\cos ^{2} \alpha} .
$$

After substituting Eq. 2 and Eq. 5 into Eq. 1, we obtain the required dependence $\varepsilon=\varepsilon(\alpha)$ for the second variant of the mutual arrangement of the cones of sliding (Fig. 3):

$$
\varepsilon=\frac{\sin 2 \alpha}{1+\sin 2 \alpha}
$$

By Eq. 6, plot 2 is plotted, which is shown in Fig. 4. Graph 2 also defines the boundary value of the angle $\alpha$ for a given value of the degree of deformation $\varepsilon$. Values of the cone angle of the roller, which are smaller than the boundary value, lead to a sharp increase in the external forces of deformation and the probability of occurrence of large structural fractures in the material of the workpiece. In addition, analysis of Eq. 6 and graph 2 shows that the greatest degree of deformation per roller should not exceed 0.5 . 


\section{Practical application of the obtained dependencies}

The area of practical application of the obtained in Eq. 4 and Eq. 6 is between graphs 1 and 2 (Fig. 4) and is limited by the values of the cone angle of the roller. The resulting graphs can be used to solve the following problems:

- determination of the taper angle of the deforming roller $\alpha$ according to the required value of the degree of deformation $\varepsilon$ of the pipe wall;

- determination of the rational value $\varepsilon$ for a known value of the angle $\alpha$.

In Fig. 4, the dashed lines indicate the scheme that must be performed to solve these problems.

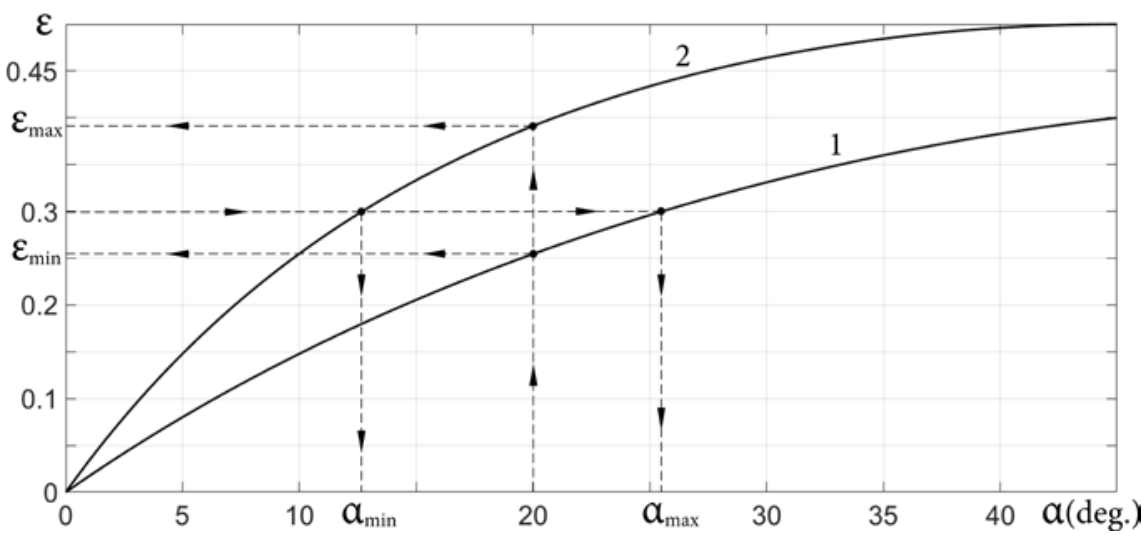

Fig. 4. Dependence of the degree of deformation of the workpiece wall $\varepsilon$ on the cone angle of the roller $\alpha: 1$ - by the Eq. $4 ; 2$ - by the Eq. $6 ; \varepsilon_{\min }$ and $\varepsilon_{\max }$ - the smallest and largest limiting values of the degree of deformation for a given angle $\alpha ; \alpha_{\min }$ and $\alpha_{\max }$ - the smallest and largest limiting values of the taper angle for a given degree of deformation

\section{Conclusion}

The developed engineering technique can be used in designing the flow forming process on the direct and reverse method, as well as for any process of pressure treatment with a local zone of deformation.

The research was conducted with the support of the program to improve competitiveness in the Ural Federal University named after the first President of Russia B.N. Yeltsin.

\section{References}

1. M.A. Greditor, Spinning and rotational extrusion (Moscow : Machinery Publishing, 1971)

2. M.Sivanandini, S.S.Dhami, B.S.Pabla, Flow Forming Of Tubes-A Review, International Journal of Scientific \& Engineering Research, 1, pp. 1-11 (2012)

3. C.C. Wong, T.A. Dean, J. Lin, A review of spinning, shear forming and flow forming processes, International Journal of Machine Tools \& Manufacture, 43, pp. 1419-1435 (2003) 
4. Q. Xiaa, G. Xiaoa, H. Longb et al., A Review of Process Advancement of Novel Metal Spinning, International Journal of Machine Tools \& Manufacture, 85, pp. 100-121 (2014)

5. N.I. Mogil'nyy, Flow forming of shell parts on machine tools (Moscow : Machinery Publishing, 1983)

6. Kalpakjian, S., Rajagopal, S., Spinning of tubes: a review, J. Appl. Metalwork, 2, pp. 211-223 (1982)

7. Plewinski, A., Denger, T., Spinning and flow forming hard-to-deform metal alloys, Arch. Civ. Mech. Eng, 9, pp. 101-109 (2009)

8. S. Ekinovica, H. Dukicb, I. Plancica, E. Begovica, Assessment of the surface topography of Al 99.5\% tubular products formed by cold flow forming technology, Procedia Engineering, 132, pp. 389-396 (2015)

9. L.A. Rakov, Flow forming on grinding machines of the type SRG (Moscow : Machinery Publishing, 1983)

10. V.I. Tregubov, Flow forming with thinning of the wall of cylindrical pipe parts on specialized equipment (Tula : Tula printing house, 2002)

11. Yakovlev S.S., Tregubov V.I., Yakovlev S.P., Flow forming of the wall of axisymmetric parts from anisotropic tube billets (Moscow : Machinery Publishing, 2009)

12. R.J. Bhatt and H.K. Raval, Comparative Study of Forward and Backward Flow Forming Process using Finite Element Analysis, Bonfring International Journal of Industrial Engineering and Management Science, 2(5), pp. 46-50 (2015)

13. S.S. Yakovlev, Forging and stamping: reference book. T. 4. Sheet stamping (Moscow : Machinery Publishing, 2010)

14. M. Joseph Davidso, K. Balasubramanian, G.R.N. Tagore, Surface roughness prediction of flow-formed AA6061 alloy by design of experiments, 202, pp. 41-46 (2008)

15. E.A. Belov, A.A. Hitryj, N.V. Evseeva, V.E. Erohin, N.A. Makarovec, R.A. Kobylin, Method for flow forming of hollow axially symmetric parts, RF Patent 2106217 (1996)

16. Tregubov V.I., Yakovlev S.S., Osipova E.V., Belov A.E., Innovative technological processes of flow forming of complex profile axially symmetric parts, Press-forging. Metal forming, 11, pp. 9-16 (2013)

17. Gryazev M.V., Yakovlev S.S., Tregubov V.I., Flow forming of axisymmetric shells of anisotropic materials with separation of deformation center, Press-forging. Metal forming, 11, pp. 35-40 (2014)

18. Cheng-Shun Chen, Jen-Hsin Ou, Huei-Guo Hu, Simulation Analysis of Spinning Forming of D6AC Ultrahigh-Strength Low-Alloy Steel, International journal of mechanics, Issue 3, Vol. 6, pp. 187-194 (2012)

19. Yakovlev S.S., Tregubov V.I., Remnev K.S., Flow forming of tube billets from anisotropic material, Press-forging. Metal forming, 11, pp. 10-16 (2011)

20. Gubkin S.I., Theory of metal forming (Moscow : Metallurgizdat, 1947)

21. Presnyakov A. A., The center of deformation in the processing of metals by pressure (Alma - Ata : Science, 1988) 